\title{
HIV/AIDS risk factors among residence students at the University of the Free State
}

\author{
G Badenhorst \\ Senior Lecturer, Department of Psychology of Education, University of the Free State, Bloemfontein
}

\author{
A van Staden \\ Lecturer, Department of Psychology of Education, University of the Free State, Bloemfontein
}

E Coetsee, M.Ed. Student

Department of Psychology of Education, University of the Free State, Bloemfontein

Key words:

HIV/AIDS, culture, gender, high-risk sexual behaviour, residence students, University of the Free State

\section{Correspondence address:}

Dr A van Staden

Internal Box 25

Department of Psychology of Education

University of the Free State

Bloemfontein

9300

Tel : (051) 401-2954

Fax : (051) 401-3898

Email : vanstadena.hum@ufs.ac.za

\begin{abstract}
Curationis 31(3): 27-35
The aim of this study is to investigate the sexual campus culture of students at the University of the Free State (UFS), by specifically focussing on gender and culture as patterns of high-risk sexual behaviour. The sample consisted of 396 participants, 211 female and 185 male students, with a mean age of 19.9 years. Sixty one percent $(61 \%)$ of the students associated themselves with a Western cultural background and 39\% with an African cultural background.
\end{abstract}

In this article an exposition is provided on information collected in a survey conducted at the UFS to help provide a better understanding of risk factors for HIV infection among UFS students in comparison with the behaviour patterns of students at other universities. Stereotypes identified as known risk factors making students at other universities more vulnerable to HIV and high-risk sexual behaviour, were also found among UFS students. Results indicated the existence of the following statistical significant correlations: African cultural students, gender and their viewpoint that there is a stronger relationship between homosexuality and HIV/AIDS; their opinion that HIV/AIDS is more strongly associated with African students. Data obtained from this survey questionnaire show that even if students have a great deal of knowledge to their disposal, and even if they recognised that they were personally at risk, some students' sexual practices and risk-taking behaviour remained unchanged. Despite the fact that the majority of students $(85 \%)$ concluded that it is unacceptable for a woman or a man to have more than one sexual partner and that it is better to wait until marriage before engaging in a sexual relationship, $17 \%$ of male students (Western culture) and $4 \%$ of female students indicated that they have had more than five sexual partners in their lives. Statistical significant correlations also existed between African students, gender and their sexual activity the last six months. Contradictory to research results reported in literature, data obtained from this survey indicate that the majority of students view condom use in a positive light $-75 \%$ of participating African students disagreed with the statement 'not using a condom during sexual intercourse shows trust in your partner'. Finally, in an interesting revelation, a general sexual culture was identified among UFS students, rather than culturally-based sexual practices. 


\section{Introduction}

South Africa has the fastest growing HIV/AIDS epidemic in the world: about $10 \%$ of those infected worldwide live in South Africa. While millions of South Africans are infected by the virus, all South Africans are affected by the pandemic (Coombe, 2002:236). Former president, Nelson Mandela, has called for a new 'war' against HIV and AIDS, arguing that it is claiming more lives in Africa, than the sum total of wars, floods and other deadly diseases, such as malaria. He said: "Its no less than a wara world war that affects all of us ultimately. We are, in this modern globalised world, each the keeper of our brother and sister. We have too often failed in that moral calling"(Carlisle, 2003:122).

Young people are especially vulnerable to HIV. Researchers estimate that in many developing countries, fifty percent or more of all HIV infections occur among people younger than 25 years. Effective HIV prevention among youth, therefore, is the key to the future course of the HIV epidemic and understanding sexual attitudes and behaviours of youth in terms of HIV risk is critical in this respect (Ma, Ono-Kihara, Cong, Xu, Zamani, Ravari \& Kihara, 2006:232). The way that we understand and conceptualised HIV/ AIDS in South Africa has changed radically in the past three decades. Researchers have realised that knowledge alone does not equate to a change in HIV risk sexual behaviour (Ross \& Deverell, 2004:200). A greater understanding of the determinants of risk-related behaviour in target populations is an important precursor to the development of successful HIV/ AIDS prevention programmes.

The rapid spread of HIV, especially amongst our youth, is a source of concern across disciplines focussing on HIV risk reduction programmes. Research findings indicate that while adolescents and young adults have knowledge about sexually transmitted infections (HIV/ AIDS), this knowledge does not necessarily translate into safe sexual behaviour (Sathiparsad \& Taylor, 2006:117). As a result, the incidence and prevalence of HIV continued to increase. A report issued by the Reproductive Health Research Unit (RHRU) concluded that gender inequalities are a major driving force behind the spread of HIV (RHRU, 2004). Consequently, HIV/AIDS was reconceptualised within the framework of 'culture and gender' (Ross \& Deverell, 2004:200).

Bayley (2003:8) takes this matter further by making a distinction between the levels of education of people being infected. He states that the loss of a small group of highly-educated persons will have a greater strategic impact on the economy of South Africa than the loss of a bigger group of lower-qualified employees.

South African students should, for this reason, be regarded as a very important target group for HIV and AIDS prevention programmes. This may, in the long run, influence the country's economical state, assist the population in taking care of HIV positive individuals, and improve the chances of preventing this destructive disease from spreading further.

Against this backdrop a questionnaire survey was conducted among students of the University of the Free State (UFS) to determine the role of culture and gender as factors in patterns of high-risk sexual behaviour among residence students.

With this goal in mind, the following questions guided this research:

- $\quad$ How do gender and culture influence high-risk sexual behaviour of UFS residence students?

- To what degree do high-risk practices of students concerning the risk of HIV infection, as influenced by gender and culture, differ at the UFS in comparison with other South African universities?

\section{Research Methodology Research design}

In this empirical study, a quantitative descriptive (survey) research design was used. Data was obtained by utilising a self-administered questionnaire. The survey questionnaire consisted of 54 items for assessing residence students' HIV/AIDS knowledge, aspects regarding stereotyping and stigmatisation and students' sexual practices, including condom usage. Socio-demographic characteristics were also noted. The questionnaire consisted of likert type questions, yes and no responses and guttman scale items.

\section{Methods}

\section{Sampling}

The population consisted of all residence students at the University of the Free State $(\mathrm{N}=3.289)$ and a representative sample $(16 \%)$ was drawn from this population. Four residences (two male and two female residences), were randomly selected from a group of 25 residences comprising of students from African or Western cultural backgrounds $(\mathrm{N}=532)$. Before the questionnaires were administered to the sample, a pilot study was carried out on a convenient sample of 20 pre-graduate education students, consisting of 10 male and 10 female students. The groups did not experience any difficulties understanding the questionnaire and therefore all the test items were retained.

The questionnaires contained no personal details that might lead to the identification of individual respondents and respondents were also assured of confidentiality in writing. Participation was on a voluntary basis and all residence students $(\mathrm{N}=532)$ of the randomly selected four residences, had an equal chance of being included in the sample group. A total number of 396 students $(211$ female and 185 male students) voluntarily participated in the study and returned completed questionnaires, representing a valid response rate of $74 \%$. It was explained to the participants that they could withdraw anytime during the administration of the questionnaire.

Sixty one percent $(61 \%)$ of the participants associated themselves with a Western cultural background and 39\% with an African cultural background. First and second year students formed the bulk of the sample, and accounted for $65 \%$ of respondents. The age distribution of the respondents varied between 18 to 22 years $($ mean age $=19.9$ years) .

Culture is a system constituting an integrated unit that plays a central part in individuals' lives, and which is also based on and influenced by religion. In the present study the participants' religious affiliation was mainly Christian (93.5\%). Participating students' sexual views may therefore have been influenced by their Christian religious views, and this possible influential power should be given the necessary recognition. 


\section{Data collection}

The questionnaire was developed through a review of South African and international literature and was designed to measure students' knowledge, attitudes and self-reported behaviour related to sexual activity and possible HIV risk infection. The Statistical Package for Social Sciences (SPSS Incorporated, 2001) was utilised to analyse the data obtained from the questionnaires. The questionnaires were administered in a group situation. Participants sat apart and were asked not to communicate with each other during the administration of the questionnaire in order to encourage honest responses.

\section{Reliability and content validity}

SAS computer software (SPSS Incorporated, 2001) was used to determine the internal consistency of the 54 item questionnaire. According to Mulder (1981:74), a coefficient of 0.80 and more is considered very high, 0.60 to 0.79 is regarded as high, 0.4 to 0.59 as moderate, 0.20 to 0.39 as low and 0.01 to 0.19 as very low. With reference to the aforementioned criteria, the calculated value (á $=0.70$ ) for the questionnaire indicated that the questionnaire complied with reliability criteria. In addition the reliability coefficient of the present study (á $=0.70$ ) seem to be in line with calculated values obtained in previous HIV/AIDS related knowledge and sexual behaviour surveys (Letamo, 2007:194; Chovwen \& Ita, 2006:88; Kalichman \& Simbayi, 2004:52).

According to Mulder (1981:217-219), the researcher must, in addition to indicating the reliability of a test, also provide information with regard to the content validity of a test - in other words, to what extent the test succeeds in measuring what it purports to measure. This type of validity is not determined statistically, but is based on the opinion of qualified persons. Not only was the advice and expertise of qualified persons obtained (cf. acknowledgements), but a thorough literature study was also conducted with regard to HIV/AIDS knowledge, including the development and administration of existing HIV/AIDS questionnaires. In light of the preceding discussions, the authors are of the opinion that the research instrument (questionnaire) that was administered in this present investigation, complied with reliability and validity criteria.

\section{Ethical considerations}

Permission was obtained from the Committee for Research Ethics (Faculty of Humanities), at the University of the Free State to conduct this study. As a process of informed consent, all students were advised of the study's purpose and when/where the survey was to be conducted. At the same time it was explained that non-participation would cause no harm to them and that the participants' privacy and confidentiality would be strictly protected as no personal identifiers were included in the questionnaire and data would be presented only in an aggregated manner.

\section{Data analysis}

For the purpose of this research, the Chisquare test $\left(\chi^{2}\right)$ of statistical significances was used to estimate the relationships between variables in the population. Neuman (2000:332) explains that, as a measurement of association, the Chisquare may be used for nominal or ordinal data.

\section{Discussion}

Data that met the following criteria will now be discussed

a) the $\chi^{2}$ had a significance/ probability of smaller than or equal to 0.05 ;

b) no more than $20 \%$ of the cells were smaller than 5 , and

c) there were no empty cells (Neuman, 2000:338-339), will be highlighted.

The independent variables are gender (male or female) and culture (African cultural background or Western cultural background). The dependent variables are identified as the practices and behaviour of students, as well as knowledge and attitudes.

\section{Culture, stereotyping and stigmatisation as risk factors for students}

In South Africa, HIV is mainly spread through unsafe heterosexual practices; however, there seems to be a general inclination among students to stereotype certain groups as the carriers of the disease (Uys \& Alexander, 2002:296). Research by Levine and Ross, 2002:104, recognized that students stigmatised the following groups as carriers of HIV: a) homosexuals, b) promiscuous people (heterosexuals or homosexuals), c) prostitutes, d) drug addicts and e) poor black people living in rural areas. Existing stereotypes were also investigated among students at the University of the Free State. When students were asked whether they perceive homosexuality or heterosexuality to be more strongly associated with HIV and AIDS, a statistical significant correlation was demonstrated between students from an African cultural background, gender and their viewpoint that there is a stronger relationship between homosexuality and HIV/AIDS $\left(\chi^{2}=26.796 ; \mathrm{df}=4 ; \mathrm{p}=0.000\right)$.

Seventeen $(17 \%)$ of males and $11 \%$ of females from an African cultural background viewed homosexuality as having the strongest relationship with HIV and AIDS. However, a total of $23 \%$ of female students in this empirical study felt neutral in this regard.

Gender also plays a role in a person's views regarding which groups they believe are more inclined to be responsible for the spread of HIV. Several researchers have found that female students have stigmatised the following groups as carriers of HIV: poor rural women, gay men, prostitutes and drug addicts (Levine \& Ross, 2002:93; Shaw, 2002:92; Uys, 2002:388). Male students are also inclined towards stigmatisation and stereotyping. This issue may cause male and female students to regard HIV as something that happens only to other people, thus giving them a false sense of security. The view that homosexuality is associated more strongly with HIV than heterosexuality supports the findings of previous studies at other universities, namely that stereotyping and stigmatisation make students more vulnerable to HIV infection (Levine \& Ross, 2002:89-108; Shaw, 2002:90-92; Marcus, 2002:23-33; Uys, 2002:382-402).

Research findings show that cultural stigmatisation also exists among students. In a study of Marcus (2002:32) students from a Western cultural background mainly viewed students from an African cultural background as the carriers of the HIV disease. The possible existence of cultural stigmatisation was also investigated at the UFS campus. A statistical significant correlation existed between students from an African cultural background, gender and their opinion that they more strongly associate students from an African cultural background with the HIV/AIDS disease $\left(\chi^{2}=30.772 ; \mathrm{df}=4 ; \mathrm{p}=0.000\right)$. Nineteen 
percent $(19 \%)$ of participating males made this association. However, the same results were not found among females from an African cultural background, as the biggest proportion (24\%) felt neutral about a person's cultural background and its association with HIV and AIDS. These findings show an interesting and new paradigm shift among male students from an African cultural background, as they appear to see their own cultural group as high-risk with regard to carrying HIV. The fact that the majority of participating female students from an African cultural background felt neutral about this issue is also a positive sign, since it may indicate that they consider the risk of contracting HIV from different cultural groups as equal. Contradictory to the research results of Marcus (2002), no statistical positive correlation was demonstrated between students from a Western cultural background and their viewpoint that students from an African cultural background are more inclined to have HIV/AIDS.

\section{Sexual activity, gender and African cultural background}

Thom and Cullinan (2003:47) postulate that students at tertiary institutions in South Africa are highly sexually active, and always have been. In addition, research findings from the study of Marcus (2002:23-33) revealed that $68 \%$ of the respondents admitted to being sexually active. This statement is also supported by Kelly (2001:32), who contends that sexual relationships among students are usually not steady, or monogamous. With regard to this empirical investigation a statistical significant correlation existed between students from an African cultural background, gender and their sexual activity in the last six months $\left(\chi^{2}=8.914\right.$; $\mathrm{df}=1 ; \mathrm{p}=0.03$ ). Of the participating 63 African males, $31 \%$ admitted to being sexually active, while $23 \%$ stated that they have not been sexually active during the last six months. Only $14 \%$ of participating African females admitted to being sexually active, while $33 \%$ indicated that they have not engaged in any type of sexual activity during the last six months.

The literature on gender provides overwhelming evidence of the influence of submissiveness. The fact that a larger percentage of male students admitted to being sexually active, may be linked to male students striving to be seen as masculine by their peers. However, it is important to mention that our data may not be a totally true reflection. According to De Wet (2006) research findings indicated that, when sexual matters are discussed, men tend to over report and woman tend to underreport.

Masculinity may be placed on a continuum between what is seen as masculine and "macho", and what is seen as refined or being a "sissy". In order to earn the label of 'masculine and macho', male students have to meet certain expectations. As at other universities the risk for male students lies in these expectations, and includes having several sexual partners (Selikow, Zulu \& Cedras, 2002:24).

When participating male and female students from Western cultural backgrounds were asked how many sexual partners they have had in their lives thus far, the following results proved to be statistically significant $\left(\chi^{2}=18.677\right.$; $\mathrm{df}=4 ; p=0.001$ ).

The majority of Western male students $(17 \%)$, admitted to having had five of more partners, while only $4 \%$ of the female students indicated that they had had more than five sexual partners. With regard to Western female UFS students, $23 \%$ of sexually active females (reflecting the majority of the female sample) stated that they had had only one sexual partner since becoming sexually active.

\section{Financial status, gender and sexual activity - African cultural perspectives}

The South African literature makes it abundantly clear that financial status is a major risk factor, often influenced by gender. A lower economic status adds to the problem of female students having unwanted sexual relationships (Evian, 2003:204). It was found that 'sugar daddy' practices and prostitution are common activities in students' lives (Kelly, 2001:30-31). Research by Selikow, Zulu and Cedras (2002:24), identifies male students' financial status as becoming a risk factor when they do not have the financial resources to buy expensive accessories. Le Clerc-Madlala (2002:30) states that, since male students see themselves as initiators of sex based on their gender norms, they may pursue several sexual relationships as an alternative route to financial status in order to gain macho status. Research findings from our empirical investigation indicate that these practices may indeed be taking place at the UFS, although it seems that the majority of students are not admitting this. When questioned about receiving gifts in exchange for sexual intercourse, a noticeable $37 \%$ of participating African male students and $51 \%$ of African female students indicated that it is unacceptable to give your sexual partner gifts in exchange for sex, bringing the total number of negative responses to $88 \%$. Moreover, a statistical significance was obtained between African students, gender and this question $\left(\chi^{2}=14.857 ; \mathrm{df}=2 ; \mathrm{p}=0.001\right)$. A total of 238 students responded to this question.

\section{The relationship between cultural background, gender and condom use}

The literature bears testimony to culture and gender as risk factors for students from different cultural backgrounds, with regard to views on condom use as a way of protection against HIV infection (Seloilwe, Jack, Letshabo, Bainame, Veskov, Mokoto, Kobue \& Muzila, 2001:204-210; Harrison, Xaba, Kunene \& Ntuli, 2001:67-69). Female students from African cultural backgrounds often believe that not using a condom will enhance their social status with their male partners. In both African and Western cultures, gender may influence the use of the male condom as a barrier against HIV and AIDS (Harrison, et al., 2001:6769). Since the male student controls the use of the male condom, every sexual encounter requires negotiation between partners (Marcus, 2002:3). The results of the following statements related to condom use will now be displayed and discussed in Table 1:
- Not using a condom during sex shows trust in your sexual partner - African cultural background.
- $\quad$ Condom use diminishes pleasure during sex - African cultural background.
- $\quad$ Condom use diminishes pleasure during sex -Western cultural background.
- Not using a condom indicates permanency in a relationship - African cultural background.
- The correlation between students from an African 


\begin{tabular}{|l|l|l|l|}
\hline Statements & $\chi^{2}$ & d & p \\
\hline "shows trust in your sexual partner" (African cultural background) & 21.407 & 2 & 0.000 \\
"diminishes pleasure during sex" (African cultural background) & 26.041 & 2 & 0.000 \\
"diminishes pleasure during sex" (Western cultural background) & 25.608 & 2 & 0.000 \\
"Not using a condom indicates permanency in a relationship" (African cultural background) & 27.867 & 2 & 0.000 \\
"concern about unwanted pregnancy during sex" (African cultural background) & 16.869 & 2 & 0.000 \\
\hline
\end{tabular}

cultural background, gender and concern about unwanted pregnancy during sex.

As indicated in Table 1, a statistically significant correlation was demonstrated between students from an African cultural background, gender and whether not using a condom during sexual intercourse shows trust in your sexual partner. The larger percentage of African males $(29 \%)$ and female students $(46 \%)$ responded 'no' to the posed question. Together, they made up a staggering $75 \%$ of the total number of participating students from an African cultural background. Contradictory to these research findings, it is reported in literature that wearing a condom during sexual intercourse shows trust in your sexual partner (Seloilwe et al., 2001:204).

Several researchers have found that the use of condoms as a way of protecting oneself against HIV infection, is viewed in a negative light (Marcus, 2002:8-9; Skidmore \& Heyter, 2000:31; Serlo \& Aavarinne, 1999:469). It is of serious concern that the majority of students from an African cultural background (male and female) were uncertain when asked whether a condom diminishes pleasure during sex. A total number of $128(56 \%)$ of African students from the sample of 228 who answered this question, showed uncertainty. From Table 1 it is further evident that a statistical significant correlation was found with regard to this statement. In addition, the majority of students from a Western cultural background $(20 \%$ of the male students and $42 \%$ female students) do not agree with the statement "condom use diminishes pleasure during sex", demonstrating a statistical significant correlation. Moreover, these research findings demonstrate that a clear distinction may be drawn between UFS students from an African or Western cultural background. Whereas students from an African cultural background showed uncertainty in this regard, the majority of students from a Western cultural background stated that they do not believe that condoms diminish pleasure during sex.

The fact that some students may choose to use condoms only during casual sexual encounters makes them vulnerable to HIV infection from their long-term sexual partners. Students who frequently make a negative association between physical pleasure and condom use, raise the risk of HIV infection. With regard to the following statement "not using a condom indicates permanency in a relationship", a statistically significant relation was demonstrated for students from an African cultural background. A total number of $66 \%$ of the participating male and female students from an African cultural background disagreed with the statement. When looking at the findings more closely, some interesting data is revealed. A greater percentage of African female students ( $43 \%$ ) than male students (23\%) disagreed with this statement. The fact that the remaining percentage of respondents either indicated uncertainty $(26 \%)$ or agreed $(8 \%)$ with this statement, can possibly be attributed to the fact that (according to research), the associations made by students between love, passion and trust combine in such a way that asking about previous sexual relationships and requesting condom use during sex are deemed inappropriate (Levine \& Ross, 2002:94).

Furthermore the data in the present study, indicated that that the majority of African UFS students (54\%) indicated that they were mainly concerned about unwanted pregnancy during unprotected sex. A statistically significant correlation existed between students from an African cultural background, gender and their opinions regarding the posed question $\left(\chi^{2}=16.869 ; \mathrm{df}=2 ; \mathrm{p}=0.000\right)$. Research findings also show that male students (32\%) seem to be more concerned about unwanted pregnancy during unprotected sex than female students $(22 \%)$. These findings concur with the findings of researchers at other universities (Marcus, 2002:8-9; Skidmore \& Heyter, 2000:31; Serlo \& Aavarinne, 1999:469).

\section{Gender and multiple partnering}

As seen in Western and African cultures in South Africa, male dominance in society plays a major role in the behaviour of female students. The female is expected to be submissive to her male partner, and to raise their children (Ferrante, 2003:342). The man is expected to be a leader in the community, and in family life (Taylor, Peplau \& Sears, 2000:247). Male students are often expected to prove their masculinity by having several sexual partners, having control over women, and owning expensive items (Selikow, et al., 2002:24). Statistical significant data that focus on gender and multiple partnering will subsequently be reflected in Tables 2 and 3 and will be discussed in the next section. The following statements were posed to the students:

\section{- It is acceptable for a woman to have more than one sexual partner-African cultural background. \\ - It is acceptable for a man to have more than one sexual partner-African cultural background.}

It is clear from Table 2 that an overwhelming majority ( $85 \%)$ of participating UFS students from African cultural backgrounds concluded that it 


\begin{tabular}{|l|l|l|l|l|l|l|}
\hline $\begin{array}{l}\text { "It is acceptable for a woman to have more than one sexual } \\
\text { partner" }\end{array}$ & \multicolumn{5}{|l|}{ SEX-AFRICAN CULTURALBACKGROUND } \\
\hline & \multicolumn{1}{|l|}{ Male } & $\%$ & Female & $\%$ & Row Total & $\%$ \\
\hline Yes & 11 & $4 \%$ & 6 & $3 \%$ & 17 & $7 \%$ \\
\hline Uncertain & 16 & $7 \%$ & 3 & $1 \%$ & 19 & $8 \%$ \\
\hline No & 84 & $36 \%$ & 117 & $49 \%$ & 201 & $85 \%$ \\
\hline Column Total & 111 & $47 \%$ & 126 & $53 \%$ & 237 & $100 \%$ \\
\hline
\end{tabular}

Table 3: Gender and multiple male partnering - African cultural background

\begin{tabular}{|c|c|c|c|c|c|c|}
\hline \multirow{2}{*}{$\begin{array}{l}\text { "It is acceptable for a man to have more than one sexual } \\
\text { partner" } \\
\text { Yes }\end{array}$} & \multicolumn{6}{|c|}{ SEX-AFRICAN CULTURALBACKGROUND } \\
\hline & $\begin{array}{l}\text { Male } \\
11\end{array}$ & $\begin{array}{l}\% \\
5 \%\end{array}$ & $\begin{array}{l}\text { Female } \\
5\end{array}$ & $\begin{array}{l}\% \\
2 \%\end{array}$ & $\begin{array}{l}\text { Row Total } \\
16\end{array}$ & $\begin{array}{l}\% \\
7 \%\end{array}$ \\
\hline Uncertain & 14 & $6 \%$ & 4 & $2 \%$ & 18 & $8 \%$ \\
\hline No & 85 & $36 \%$ & 117 & $49 \%$ & 202 & $85 \%$ \\
\hline Column Total & 110 & $47 \%$ & 126 & $53 \%$ & 236 & $100 \%$ \\
\hline
\end{tabular}

$\begin{array}{lll}\chi^{2}=22.889 & \mathrm{df}=3 & \mathrm{p}=0.000\end{array}$

Table 4: Absence from home and sexual opportunities - African cultural background

\begin{tabular}{|l|l|l|l|l|l|l|}
\hline $\begin{array}{l}\text { "Being away from home makes it easier to experiment with } \\
\text { sex" }\end{array}$ & \multicolumn{5}{|l|}{ SEX-AFRICAN CULTURALBACKGROUND } \\
\hline Yes & Male & $\%$ & Female & $\%$ & Row Total & $\%$ \\
107 & 43 & $27 \%$ & 44 & $19 \%$ & $46 \%$ \\
\hline Uncertain & 23 & $10 \%$ & 19 & $8 \%$ & 42 & $18 \%$ \\
\hline No & 24 & $10 \%$ & 60 & $26 \%$ & 84 & $36 \%$ \\
\hline Column Total & 110 & $47 \%$ & 123 & $53 \%$ & 233 & $100 \%$ \\
\hline
\end{tabular}

$\chi^{2}=18.516$

was unacceptable for a woman to have more than one sexual partner $\left(\chi^{2}=11.845\right.$; $\mathrm{df}=2 ; \mathrm{p}=0.003$ ).

From Table 3 it is further evident that the majority of African students $(85 \%)$ indicated that it is unacceptable for a man

$\mathrm{df}=3$

$$
\mathrm{p}=0.000
$$

to have more than one sexual partner. A statistically significant relation was demonstrated for UFS students from an African cultural background regarding this statement $\left(\chi^{2}=22.889\right.$; $\mathrm{df}=3 ; \mathrm{p}=$ 0.000 ). However, this finding seems to be contradicted in literature. Literature findings suggest that having more than one sexual partner is considered more acceptable for male students than for female students (Coetsee, 2007:13).

From the findings and discussions above the researchers can conclude that it 


\begin{tabular}{|l|l|l|l|l|l|l|l|}
\hline $\begin{array}{l}\text { "I support the belief that it is better to wait until you are } \\
\text { married before having sex" }\end{array}$ & \multicolumn{7}{|l|}{ SEX-AFRICANCULTURALBACKGROUND } \\
\hline Yes & Male & $\begin{array}{l}\% \\
81\end{array}$ & $\begin{array}{l}\text { Female } \\
\%\end{array}$ & $\begin{array}{l}\text { Row Total } \\
416\end{array}$ & $\begin{array}{l}\% \\
197\end{array}$ & $84 \%$ \\
\hline Uncertain & 16 & $7 \%$ & 5 & $2 \%$ & 21 & $9 \%$ \\
\hline No & 13 & $5 \%$ & 4 & $2 \%$ & 17 & $7 \%$ \\
\hline Column Total & 110 & $47 \%$ & 125 & $53 \%$ & 235 & $100 \%$ \\
\hline
\end{tabular}

could be a general campus culture at the UFS to regard multiple partnering as unacceptable, irrespective of the gender of the person.

\section{Being away from home makes is easier to experiment with sex - African cultural perspectives}

When students leave their homes, they are also leaving behind the rules and regulations of a controlled environment; in addition, they are at an age where they enjoy autonomy (Strydom \& Strydom, 2002:263-264). Thus, this newfound freedom may make it easier for them to experiment with sex.

Findings from Table 4 indicate that a statistically significant relationship exist between students from an African cultural background, gender and their opinions regarding "being away from home makes it easier to experiment with $\operatorname{sex} "\left(\chi^{2}=18.516 ; d f=3 ; p=0.000\right)$.

A majority of the students (46\%) concurred that it is easier to experiment with sex when you are away from home. In addition, closer inspection of the research findings in Table 4 reveals an interesting disparity between the responses of female and male UFS students from African cultural backgrounds.

Twenty seven $(27 \%)$ of the males agreed that being away from home makes it easier to experiment with sex. In contrast to the males' opinion, the majority of female students supported the opposite view, with $26 \%$ believing that being away from home does not make it easier to experiment with sex. In general, however, the majority of participating students agreed with this statement.

\section{It is better to wait until you are married before having sex - African cultural perspectives}

When reflecting on the study in general, the question arose whether students would still choose to engage in sexual activities if they had possessed the life experience they have gained since becoming sexually active. The following findings were demonstrated:

It is clear from Table 5 that the majority of the participating sample (84\%) stated that they thought it was better to wait until marriage before having sex. A statistical significant correlation was obtained $\left(\chi^{2}\right.$ $=15.852 ; \mathrm{df}=2 ; \mathrm{p}=0.000)$. This results however, seem to contradict previous data obtained from this questionnaire which focus specifically on the high risk sexual behaviour of students (sexual activity the past six months and the number of sexual partners they have had). An assumption is that this point of view may be ascribed to experience gained from sexual activity, or could be a cultural belief that is not being applied.

\section{Conclusion}

An in-depth analysis was done by using contingency tables to evaluate information collected during a survey in August 2006 among residence students at the UFS. Main outcome measures included establishing possible relationships that existed between culture (African and Western), gender and students' viewpoints regarding HIV/ AIDS-related knowledge, stereotypes and high risk sexual behaviour.

Data in this empirical study revealed the following important statistical significant relationships between UFS students' cultural background, gender and certain viewpoints regarding high risk sexual behaviour. The view that homosexuality is associated more strongly with HIV/ AIDS than heterosexuality supports the findings of previous studies at other universities, namely that stereotyping and stigmatisation make students more vulnerable to HIV/AIDS infection. Twenty eight $(28 \%)$ of students from African cultural backgrounds viewed homosexuality as having the strongest association to HIV/AIDS, while data regarding possible cultural stigmatisation indicated that African students more strongly associated African students with the HIV/AIDS disease. Although the majority of African students indicated that it is unacceptable to give your sexual partner gifts in exchange for sex, data obtained from the survey revealed that these practices may indeed be taking place at the University of the Free State.

A significant statistical relationship was found in both students from African and Western cultural backgrounds when asked whether they believed that condom use diminishes pleasure during sex. The majority of students from a Western background disagreed, whereas the majority of male students from an African background agreed and most females were uncertain.

The general conclusion that can be drawn is that the views of students from a Western cultural background on sexual matters are more closely associated than those of students from an African cultural background, where there is a big difference between the views of male and female students within this group, on sexual matters. 


\section{Recommendations}

Data obtained from this empirical study could be useful for the design and improvement of HIV/AIDS prevention outreach programs among university students. The following recommendations may be considered:

- To lay a foundation for prevention through behavioural change, we need to make the study of sexual behaviour a priority.

- $\quad$ Prevention efforts must target the totality of students' social environment - it must be aged specific, gender specific and culture specific.

\section{References}

BAYLEY, D 2003: The white collar HIV Myth. South African Banker. 100(1), 8-9.

CARLISLE, D 2003: AIDS will affect us all eventually, Mandela tells London Audience. bmj.com/content/vol327/ issue 7407/\#NEWS ROUNDUP. Accessed 12 November 2006.

CHOVWEN, CO \& ITA, M 2007: Influence of gender, self-consciousness and stigmatisation on perceived acceptance among people living with HIV in Nigeria. African Journal of Aids Research, 2007(1):87-90.

COETSEE, EE 2007: HIV risk factors: The sexual behaviour of South African students. Bloemfontein: University of the Free State. (Masters' thesis)

COOMBE, C 2002: HIV/AIDS and trauma among learners: Sexual violence and deprivation in South Africa. (In Maree, K \& Ebersöhn, L, eds. 2002: Lifeskills and Career Counselling. Sandown: Heinemann Publishers (Pty) Ltd., p. 235 249).

DE WET, M 2006: Interview on 11 April 2006 with an associate research advisor of the University of the Free State regarding data information (Amercian Sex lifes) shared by Mick Cooper in pro seminars attended at the University of Michigan.

EVIAN, C 2003: Primary AIDS care: a practical guide for primary personnel in the clinical and supportive care of people with HIV/AIDS. Houghton: Jacana Education.
FERRANTE, J 2003: Sociology: a Global Perspective. Belmont: Thompson/ Wadsworth Learning.

HARRISON, A; XABA, N; KUNENE, P \& NTULI, N 2001: Understanding safe sex: gender narratives of HIV and pregnancy prevention by rural South African school-going youth. Reproductive Health Matters. 9(17):6371.

KALICHMAN, SC \& SIMBAYI, LC 2004: Sex during genital bleeding and risks for HIV infection: preliminary study of sexually transmitted infection clinic patients in Cape Town, South Africa. African Journal of Aids Research, 3(1):51 55 .

KELLY, MJ 2001: Challenging the challenger: understanding and expanding the responses of Universities in Africa to HIV/AIDS. Washington D.C.: ADEA Working Group on Higher Education, World Bank.

LE CLERC-MADLALA, S 2002: Youth, HIV/AIDS and the importance or sexual culture and context. Social Dynamics. 28(1):20-41

LETAMO, G 2007: Misconceptions about HIV prevention and transmission in Botswana. African Journal of Aids Research. 6(2): 193-198.

LEVINE, S \& ROSS, F 2002: Perceptions of and attitudes to HIV/AIDS among young adults in Cape Town. Social Dvnamics. 28(1):89-108.

MA, Q; ONO-KIHARA, M; CONG, L; XU, G; ZAMANI, S; RAVARI, SM \& KIHARA, M 2006: Sexual behaviour awareness of Chinese university students in transition with implied risk of sexually transmitted diseases and HIV infection: A cross-sectional study. http:/ /www.biomedcentral.com/1471-2458/6/ 232. Accessed 8 August 2007.

MARCUS, T 2002: Kissing the Cobra: sexuality and high risk in a generalized epidemic - a case study of white university students. African Journal of AIDS Research. 1(1):23-33.

MULDER, JC 1981: Statistiese tegnicke in Opvoedkunde. Pretoria: HAUM.

NEUMAN, WL 2000: Social research methods: Qualitative and Quantitative
Approaches. Allyn \& Bacon: USA.

REPRODUCTIVE HEALTH RESEARCH UNIT 2004: HIV and sexual behaviour among young South Africans: a national survey of 15-24 year olds. http:www.rhru.co/za/images/doc/ nat $\%$ survev $\%$. Accessed 1 December $\underline{2006}$.

ROSS, E \& DEVERELL, A 2004: Psychosocial issues in HIV/AIDS. (In Ross, E \& Deverell, A, eds. 2004: Psychosocial approaches to health, illness and disability. Pretoria: Van Schaik Publishers, p. 198-219)

SPPS INCORPORATED 2001: SPPS User's guide. New York.

SATHIPARSAD, R \& TAYLOR, M 2006: 'Diseases come from girls': perspectives of male leamers in rural Kwa Zulu-Natal on HIV infections and AIDS. Journal of Education. 38:117-138

SELIKOW, TA; ZULU, B \& CEDRAS, E 2002: The ingagara, the regte and the cherry: HIV/AIDS and youth culture in contemporary urban townships. Agenda. 53:22-32.

SELOILWE, E; JACK, A; LETSHABO, K; BAINAME, K; VESKOV, D; MOKOTO,M; KOBUE, M \& MUZILA, R 2001: HIV/AIDS at the University of Botswana: behavioural and prevention issues. Pula: Botswana Journal of African Studies, 15(2):204-210.

SERLO, KL \& AAVARINNE, H 1999: Attitudes of university students towards HIV/AIDS. Journal of Advanced Nursing. 29(2):463-470.

SHAW, M 2002: HIV/AIDS: back to basics: Health. Pace. 90-92.

SKIDMORE, D \& HEYTER, E 2000: Risk and sex: ego-centricity and sexual behaviour in young adults. Health. Risk \& Societv, 2(1):23-32.

STRYDOM, H \& STRYDOM, C 2002: Theories and models serving as a basis for design of a HIV/AIDS prevention programme for students. Social Work. 38(3):261-277.

TAYLOR, SE; PEPLAU, LA \& SEARS, DO 2000: Social Psychology: Tenth Edition. Prentice Hall: New Jersey.

THOM, A \& CULLINAN, K 2003: Sex 
and the students. Fair Lady. December $2003,47-52$.

UYS, T 2002: Students, sex and AIDS: a methodological controversy. Society in Transition. 33(3):382-402.

UYS, T \& ALEXANDER, P 2002: AIDS and sociology; current South African research. Society in Transition. 33(3):295311.

\section{Acknowledgement}

We would like to thank and acknowledge Dr Petro Basson, head of the HIV/AIDS Centre at the University of the Free State and Natalé le Roux, research psychologist/research assistant at the Department of Psychology of Education at the University of the Free State for their guidance and support with this study. 